between women in terms of probability of risk to an unborn child and offer a test which, to be effective in population terms, will lead to being offered termination of an abnormal fetus. Such screening would generally be for Down's Syndrome and would only be performed after agreement of the mother to abort an affected fetus. To respond to a woman's request for such tests may be morally acceptable, but to sow seeds of doubt in the mind of a pregnant mother who hitherto had no worries, and to offer her the death of her baby as the sole solution may be ethically unacceptable.

There is no evidence put forward as to who these high-risk women are, nor of the proportion of women in these groups likely to find this method of prevention morally or ethically acceptable. It would have been interesting to have examined the acceptability and efficacy of such programmes elsewhere. In addition, one would have expected a health economist to have looked more closely at the issues of likely cost-effectiveness of such a screening policy. The application of currently accepted criteria for monitoring a screening programme would have been illuminating.

Despite these reservations, the author reflects a body of current opinion, concerned to make things work, to provide 'good' community care, though possibly at the expense of families and the community, and to involve statutory and voluntary sectors more in working together. The problems have been realistically analysed but a lot more effort must be directed to finding convincing and ethically acceptable solutions.

DEIRDRE CUNNINGHAM

Department of Community Medicine, Paddington and North Kensington Health Authority, London

\section{The Physician and the Hopelessly Ill Patient: Legal, Medical and Ethical Guidelines}

Society for the Right to Die, 92 pages, New York, \$5.00, Society for the Right to Die, 1985

This volume is divided into three sections. The first, short section is a reprint of an article which was originally published in The New England Fournal of Medicine in 1984 and is a synthesis of the thinking of ten American physicians. This article was written in an attempt to begin to examine publicly the responsibility of physicians towards the hopelessly ill patient. The article deals with the ethical dilemmas of whether life should be sustained at all costs or whether its quality should be taken into account. It perceives four general levels of care which should be considered and discussed with the patient ranging from emergency resuscitation to general nursing care which simply makes the patient comfortable. The article considers both the competent and incompetent patient and argues for a sensible approach to patients and relatives who, if at all possible, have the right to be involved in any decision-making. Further, it affirms the limited usefulness of 'The Living Will' as a real assistance to the physician trying to ascertain the best course of treatment for the dying patient.

The second section of the book is a compilation of questions and answers on legal aspects of allowing patients to die. Here the book moves from the ideal or theoretical to the pragmatic. This begins to put into perspective what courses of action are possible, when the patient's wishes should be heeded and the doctor's responsibilities when dealing with the hopelessly ill person.

The final section of this book takes the questions a stage further by giving an up-to-date resumé of right to die and living will legislation and case law State by State. What becomes apparent from this is the sheer complexity and variance in legislation in the United States. Since 1976 some 36 States have enacted living will laws. Although these share common features no two are precisely identical. This is further complicated by the fact that where a State has no legislation or case law about the right to die. . . 'the law of other States may exert influence and may indicate general trends, but it is not binding'.

This book is a fascinating vignette on how the United States is dealing with one of the most important ethical considerations of the medical profession; the right of anyone to selfdetermination at the most profound level. It is generally accepted that in a developed society ethical principles will be enshrined in legislation. However, reading this book gives one a sad reminder of the chaos which ensues when a medical profession is beset by rampant and costly litigation.

RODERICK COSH

Chaplain's assistant,

The Royal Marsden Hospital, London

\section{The Right to Die - Understanding Euthanasia}

Derek Humphry and Anne Wickett, 353 pages, London, £15, The Bodley Head, 1986

The uncomfortable paradox of modern $\stackrel{\mathbb{D}}{\varnothing}$ medical advance is that technology can $\stackrel{\infty}{\infty}$ often create much suffering particularly in a terminally ill, elderly patient who would much prefer 'to go to sleep now' as in the reported last words of 92-yearold Lord Stockton, Harold MacMillan. To go gently into that good night is the preferred way of death for most of us $\vec{\omega}$ but the dilemma of modern medicine $\omega$ is that the ethical insistence on the sanctity of life often means for aged $\vec{\rightarrow}$ patients who might have slipped away 음 peaceably only a generation ago, that death is a technological battle to keep patients alive - no matter what the quality of life is. The medical and ethical commitment to preserving life even against a suffering incurable patient's wishes is the subject of The Right to Die by Derek Humphry and Anne Wickett.

This wide-ranging and closely arguet study, subtitled Understand Euthanasia, traces the historicall perspective of 'mercy-killing' and the roots of the religious and cultural concept of the sanctity of life.

The authors make no secret of their position and argue fluently that $\frac{0}{3}$ euthanasia is the compassionate response where terminally ill but competent people request help to die. It is inhumane, they argue, to keep people technically alive when they are in a hopeless condition, when they are suffering and when they have made it clear they wish to die.

Derek Humphry, an English journalist who now lives in America, 음 writes from first-hand experience in that in 1978 he wrote Fean's Way, an account of how he helped his terminally ill wife to die. He was investigated by $N$ the Director of Public Prosecutions as $N$ to his role in his wife's death but he was not prosecuted. Now with Anne Wickett, his co-author, he has founded $\bar{\gamma}$ the Hemlock Society which urges the rights of people to be helped to die, $\frac{2}{\Phi}$ either in a passive or even in an active $\stackrel{\mathscr{O}}{\longrightarrow}$ way, when medical help can only prolong what they consider to be 'dying' and not living.

However, the study gives a fair and $\frac{\mathrm{Q}}{\Phi}$

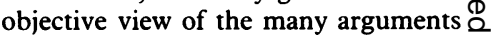
against euthanasia, as an Orwellian 